Psychiatrists confirms, the main way to reduce alcohol problems is to contain, and probably reduce, national alcohol consumption. Despite an initial wariness Sir John Crofton, an eminent physician and chairman of the committee that produced a much praised Scottish report on alcohol, 4 agreed to be chairman of the forum. He wanted to test the drink trade's commitment to reducing alcohol problems. He asked the trade to produce a "substantial sum" to fund the forum's work, and the result was that he was promptly sacked. Since then nobody has been "mug enough" to take on chairing this impotent forum, and the last plank of the government's alcohol policy has collapsed.

The Royal College of Psychiatrists makes little or no mention of all this politics in its high minded and clearly written report. But the truth is that much is known about what could be done to reduce alcohol problems, and the report spells out some of those responses. What is lacking is the political will to make the responses and public pressure to make the politicians act-and neither political will nor public pressure is likely to materialise until we have much more effective campaigning organisations.

Assistant Editor,

RICHARD SMITH

AMJ

1 Special Committee of the Royal College of Psychiatrists. Alcohol: our favourite drug. London: Tavistock Publications, 1986

2 Paton A. The politics of alcohol. Br Med f 1985;290:1-2.

3 Department of Health and Social Security. National voluntary organisations and alcohol misuse. London: DHSS, 1982.

4 Scottish Health Education Co-ordinating Committee. Health education in the prevention of alcohol related problems. Edinburgh: Scottish Home and Health Department, 1985.

\section{Treating ovarian cancer}

Ovarian cancer accounts for $6 \%$ of all deaths from cancer in women in Britain and is the commonest cause of death from gynaecological malignancy. Most patients present with tumours extending beyond the pelvis, and the five year survival is inversely related to the stage of the disease as defined by the International Federation of Gynaecology and Obstetrics: for those with stage IIb disease (growth in one or both ovaries with extension to other pelvic tissues) the five year survival is $42 \%$; while for those with stage IV (growth in one or both ovaries with distant metastases, or a pleural effusion containing cancerous cells, or metastases to liver parenchyma) it is $4 \%{ }^{1}$

Radiotherapy, it has been suggested, might "cure" patients with disease up to stage III (growth in one or both ovaries with intraperitoneal metastases outside the pelvis, or tumour in retroperitoneal lymph nodes, or both; or tumour limited to the true pelvis with histologically confirmed malignant extensions to small bowel or omentum). ${ }^{2}$ Other groups, and particularly British ones, have not, however, been able to confirm these results. Patients with more extensive disease have been treated with chemotherapy, usually_until recently_alkylating agents used singly.

The response rates range from $36 \%$ to $65 \%$ (duration 10-14 months), but only a few patients achieve complete remission-and the five year survival is a dismal $0.9 \% .^{3}$

Thus, in an attempt to improve survival, using two or more drugs in combination was a logical step, particularly in view of the success in treating other tumours-notably the lymphomas and Hodgkin's disease. The first study to suggest that this approach improved survival compared a four drug combination (hexamethylmelamine, cyclophosphamide, methotrexate, and fluorouracil) with melphalan. ${ }^{4}$ Improvement was seen only in patients with stage II and III tumours, however, and even these results have not been confirmed by other groups. ${ }^{56}$ Most later drug combinations include cisplatin, and, while toxic, such combinations are highly effective-even for patients with advanced disease.

Are such treatments, though, of long term benefit to the patient? Some controlled studies have shown a survival advantage with cisplatin used in combination ${ }^{7.9}$; others have not. ${ }^{10-13}$ No study, however, has many patients alive after five years irrespective of whether they were showing an improved "survival" at an earlier stage.

So what is the optimum management of patients with stage III and IV ovarian cancer? Can drug combinations containing cisplatin or other toxic drugs be justified, or should we revert to treatment with single agent alkylating agents, particularly for those patients with bulk disease?

The initial surgical management may be crucial. Griffiths was the first to show that the amount of tumour left after an operation was an important prognostic variable. ${ }^{14}$ Survival was uniformly poor if the diameter of the largest residual mass was greater than $1.5 \mathrm{~cm}$ irrespective of tumour volume before resection. ${ }^{14}$ Therefore all patients should have as much tumour as possible resected at the first operation. Also the surgeon should remove the greater omentum and excise, as far as possible, affected lymph nodes. Computed tomography or nuclear magnetic resonance can help identify such nodes. ${ }^{15}$

After surgery patients may be divided into two groups. Those with "minimal residual disease" have by far the better prognosis, and most specialised centres continue to treat such patients with a drug combination containing cisplatin despite its toxicity; this group will probably survive longer with this treatment than if a single agent were used. For the remainder with bulk disease, we think that intensive chemotherapy may still be justified provided there are no contraindications, such as advanced age or poor general health. About half of patients treated with a drug combination will achieve a complete remission, ${ }^{16}$ but relapse is common once treatment is stopped.

Intuitively, we feel that if only there were a means of maintaining the initial remission then a considerable improvement in survival would result. The recent use of monoclonal antibodies has allowed more precise monitoring of treatment, ${ }^{17}$ and such assays could help define the optimum number of treatments, the timing and place of a second laparotomy, and the duration of maintenance treatment. Therefore, such patients should continue to be treated but only in specialised centres with an interest in treatment. Only in this way can trials be conducted to define the optimum treatment and to test new treatments. Ideally all such patients should be included in a clinical trial.

Are there any new drugs on the horizon? The answer is only carboplatin. Whether it will replace cisplatin because of its lower nephrotoxicity is debatable. We think that the response rate will be similar to that with cisplatin, that carboplatin will probably be more myelosuppressive, and that overall survival will not be much improved. Giving platinum intraperitoneally is attractive as it achieves high intracellular drug concentrations in small tumour deposits, and this may be a way forward for those patients with minimal residual disease. . $^{1820}$

Managing advanced ovarian cancer remains difficult, and a simple solution is unlikely to emerge in the foreseeable future. Just as important as concentrating on those who will benefit, however, is that we should not waste resources by 
overtreating patients with no reasonable chance of long term benefit.

R W BURSLEM

Honorary Consultant Gynaecologist,

Withington Hospital

West Didsbury,

Manchester M20 8LR

P M WILKINSON

Consultant Physician/Clinical Pharmacologist,

Christie Hospital,

Manchester M20 9BX

1 Richardson GS, Scully RE, Nikrui N, Nelson JH Jr. Common epithelial cancer of the ovary N Engl f Med 1985;312:415-24.

2 Dembo AS, Bush RS. Radiation therapy of ovarian cancer. In: Griffiths CT, Fuller AF Jr, eds. Gynecological oncology. The Hague: Martinus Nijhoff, 1983:263-98.

3 Young RC. Gynecologic malignancies. Cancer Chemotherapy Annual 1979;1:340-75.

4 Young RC, Chabner BA, Hubbard SP, et al. Prospective trial of melphalan (L-PAM) versu combination chemotherapy (Hexa-CAF) in ovarian adenocarcinoma. N Engl f Med 1978;299. 1261-6.

5 Bush RS. Therapy of advanced ovarian carcinoma. $N$ Engl f Med 1979;22:676.

6 Barlow JJ, Blumenson LE. Therapy of advanced ovarian carcinoma. $N$ Engl f Med 1979;22:676 Bruckner $\mathrm{HW}$, Cohen CJ, Goldberg JD, et al. Improved chemotherapy for ovarian cancer with cis-diamminedichloroplatinum and adriamycin. Cancer 1981;47:2288-94.

8 Decker DG, Flemming TR, Malkasian GD, et al. Cyclophosphamide plus cisplatinum in combination: treatment programme for stage III and IV ovarian carcinoma. Obstet Gynecol

9 Neijt JP, Ten Bokkel Huinink WW, Van der Burg MEL, et al. Randomised trial comparing two combination chemotherapy regimens (Hexa-CAF vs Chap 5) in advanced ovarian carcinoma. Lancet 1984;ii:594-600.

10 Carmo-Pereira J, Costa F, Henriques E, et al. Advanced ovarian carcinoma: a prospective and randomized trial of cyclophosphamide versus combination cytotoxic chemotherapy (HexaCAF). Cancer 1981;48:1947-51.

11 Sturgeon JF, Fine S, Gospodarowicz MK, et al. A randomized trial of melphalan alone versus combination chemotherapy in advanced ovarian carcinoma. Proceedings of the American Society of Clinical Oncology 1982;1:108.

12 Bell DR, Woods RL, Levi JA, et al. Advanced ovarian cancer: a prospective randomized trial of chlorambucil vs combined cyclophosphamide and cis-diamminedichloroplatinum. Aust NZ Med 1982;12:245-9.

13 Williams CJ, Mead GM, Macbeth FR, et al. Cisplatin combination chemotherapy versus chlorambucil in advanced ovarian carcinoma; mature results of a randomized trial. $7 \mathrm{Clin}$ Oncol 1985;3:1455-62.

14 Griffiths CT, Fuller AF. Intensive surgical and chemotherapeutic management of advanced ovarian cancer. Surg Clin North Am 1978;58:131-42.

15 Johnson RJ. X-ray techniques and ultrasound in diagnosis and staging. In: Bleehen NM, ed. Ovarian cancer. Berlin: Springer, 1985:46-52.

16 Ehrlich CE, Einhorn L, Stehman FB, Blessing J. Treatment of advanced epithelial ovarian cancer using cisplatin, adriamycin, and cytoxan-the Indiana University experience. Clin Obster Gynaecol 1983:10:325-35.

17 Canney PA, Moore M, Wilkinson PM, James RD. Ovarian cancer antigen CA125: a prospective clinical assessment of its role as a tumour marker. Br f Cancer 1984;50:765-9.

18 Howell SB, Pfeifle CE, W'ung WE, Olshen RA. Intraperitoneal cis-diamminedichloroplatinum with systemic thiosulfate protection. Cancer Res 1983;43:1426-31.

$19 \mathrm{McVie}$ JG, Ten Bokkel Huinink WW, Aartsen E, et al. Intraperitoneal chemotherapy in minimal ovarian cancer with cisplatin and iv sodium thiosulfate protection. Proceedings of the American Society of Clinical Oncology 1985;4:125.

20 Markman M, Howell S, Cleary S, Lucas W. Survival following cisplatin (DDP)-based intraperitoneal chemotherapy for refractory ovarian carcinoma. Proceedings of the American Society of Clinical Oncology 1986;5:113.

\section{Indium-111 leucocyte scanning-underused?}

Indium-111 leucocyte scanning is an accurate method of diagnosing focal sepsis, and is used to localise and measure the activity of disease in some inflammatory conditions. It is, however, less widely used than other nuclear medicine investigations, and some departments do not perform it at all. What is the clinical role of the test, and where should it be available?

Labelling leucocytes means separating them from other blood cells and incubating them with an ${ }^{11}$ In complex, usually oxine or tropolone. The labelled cells are then reinjected and the patient scanned. Donor cells can be used in neutropenic patients. ${ }^{12}$ Because patients do not need preparation and contrast media are unnecessary the test is particularly useful postoperatively or in severely ill patients. Some abscesses may be identified 30 minutes after reinjecting labelled cells, although the maximum sensitivity of detection is not reached for 24 hours. $^{3}$ Cells are taken up by the reticuloendothelial system in the liver, spleen, and bone marrow, and additional radiopharmaceuticals may be needed to detect sepsis in these organs. ${ }^{45}$ The fact that the bowel and kidneys do not take up the labelled cells is an important advantage in investigating intra-abdominal disease. All areas of the body can be examined, and often unsuspected extraabdominal foci of infection are identified. ${ }^{6}$ Studies have

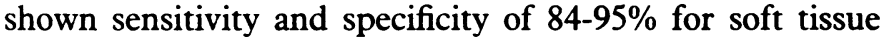
infection ${ }^{367}$; false positive scans occur particularly with haematomas or coexisting inflammatory disease, and false negatives with chronic sepsis. ${ }^{8}$ New insights have also been gained: serial imaging has shown that intra-abdominal abscesses often communicate with the bowel. ${ }^{9}$ This was not appreciated previously since the site of the communication is often not apparent even when open surgical drainage is performed.

Ultrasound scanning and computed tomography are also used to localise abdominal sepsis. Few clinical trials have compared these techniques. ${ }^{70}$ All the techniques have limitations, and sometimes more than one will be needed. When clinical localising signs are present or when results are needed urgently then ultrasound scanning or computed tomography is likely to be the first investigation, the choice depending on the localising site. "In labelled leucocyte scanning will be needed in some cases, particularly when it is not clear if a fluid collection is purulent or immediately after operation when ultrasound scanning and computed tomography may be technically difficult. Centres without computed tomography will rely heavily on leucocyte scanning as the first investigation. When there are no localising signs leucocyte scanning should be the first investigation ${ }^{6}{ }^{10}$; ultrasound scanning or computed tomography may occasionally be needed as well either because the result of the leucocyte scan is equivocal or to help plan drainage. Abscesses with enteric drainage have fewer localising signs and an appreciably lower detection rate by ultrasound scanning.

Labelled leucocyte scanning is also valuable for identifying acute osteomyelitis unless the infection is in the spine-the reason for the lower sensitivity at this site is unknown. ${ }^{11}$ The test is less sensitive for chronic bone infection (probably because of its characteristically poor granulocyte infiltration) and is less sensitive but more specific than gallium-67 citrate scanning for identifying infection around prosthetic hips. ${ }^{13}$

Increasing attention has been paid recently to using leucocyte scanning for other inflammatory conditions. ${ }^{14}$ In inflammatory bowel disease areas of abnormal bowel can be localised and the response to treatment monitored. ${ }^{15-17}$ Counting faecal ${ }^{111}$ In activity is the most precise method for measuring disease activity, particularly if pure granulocyte preparations are labelled. The results of scanning in acute pancreatitis correlate well with other measures of disease activity and accurately predict outcome. ${ }^{18}$ The exact role of the technique in these inflammatory conditions is still being defined but is likely to be for monitoring the progression of the disease and the response to treatment rather than for making a diagnosis

There are two main reasons why ${ }^{11}$ In leucocyte scanning is less widely available than other nuclear medicine investigations. Firstly labelling leucocytes with ${ }^{111}$ In is more complicated and time consuming than preparing other radiopharmaceuticals, taking up to two hours a patient. Skill in labelling cells can, however, be readily acquired by staff trained in preparing radiopharmaceuticals even when only modest facilities are available, ${ }^{19}{ }^{20}$ and newer kit preparations may further simplify the procedure. ${ }^{21}$ The $£ 60$ cost of the 